\title{
Rosiglitazone-enriched diet did not protect liver ischemia-reperfusion injury in a rat model $^{1}$
}

\author{
Dieta enriquecida com rosiglitazona não protege a lesão de isquemia e reperfusão hepática \\ em modelo experimental no rato
}

\author{
Antonio Roberto Franchi Teixeira', Nilza Trindade Molan", Marta Bellodi-Privato"II, Ana Maria Coelho"I, Kátia Ramos \\ Leite $^{\mathrm{IV}}$, Antônio Carlos Segurov ${ }^{\mathrm{V}}$, Telésforo Bacchella ${ }^{\mathrm{VI}}$, Marcel Cerqueira César Machado ${ }^{\mathrm{VI}}$

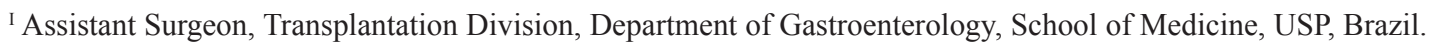 \\ II Pharmacist, Transplantation Division, Department of Gastroenterology, School of Medicine, USP, São Paulo, Brazil. \\ III Post-Doctor Student, Transplantation Division, Department of Gastroenterology, School of Medicine, USP, São Paulo, Brazil. \\ Iv Assistant Pathologist, Department of Urology, School of Medicine, USP, São Paulo, Brazil. \\ ${ }^{v}$ Associate Professor, Department of Nephrology, School of Medicine, USP, São Paulo, Brazil.

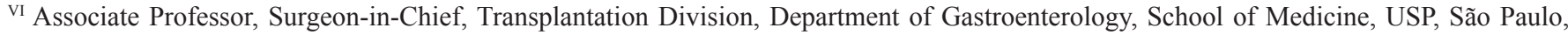 \\ Brazil.

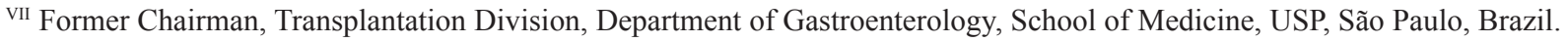

\begin{abstract}
Purpose: To determine whether rosiglitazone-enriched diet offer protection in a classical model of liver ischemia-reperfusion injury in rats. Methods: Two days before the experiment, rats were divided into 2 groups: Control Group ( $\mathrm{n}=13$ ) rats fed with standard diet; Rosi Group ( $\mathrm{n}=13)$ : rats fed with a powdered standard diet supplemented with rosiglitazone. The animals were submitted to liver ischemia-reperfusion by clamping the pedicle of median and left anterolateral lobes. After 1 hour of partial hepatic ischemia, the clamp was removed for reperfusion. After 2 or 24 hours (Control and Rosi Groups), blood was collected for enzymes and cytokines analysis. Ischemic and non-ischemic liver were collected for malondialdehyde analysis and histological assessment. Lungs were removed for tissue myeloperoxidase quantification. Results: There were no statistical differences between groups for all analysed parameters. Conclusion: In this model, rosiglitazone-enriched diet did not protect liver against ischemia-reperfusion injury.
\end{abstract}

Key words: Ischemia. Reperfusion. Liver. Rats.

\section{RESUMO}

Objetivo: Determinar se a dieta enriquecida com rosiglitazona oferece proteção em um modelo clássico de lesão de isquemia e reperfusão hepática em ratos. Métodos: Dois dias antes do experimento, os ratos foram divididos em 2 grupos: Grupo Controle $(n=13)$ : ratos alimentados com dieta padrão; Grupo Rosi $(n=13)$ : ratos alimentados com dieta em pó padrão enriquecida com rosiglitazona. Os animais foram submetidos à isquemia e reperfusão hepática por clampeamento do pedículo dos lobos médio e anterolateral esquerdo. Após 1 hora de isquemia, o clampe foi removido para a reperfusão. Após 2 ou 24 horas (Grupos Controle e Rosi), o sangue foi coletado para análise de enzimas e citocinas. Os fígados isquêmico e não isquêmico foram coletados para análise de malondialdeído e avaliação histológica. Pulmões foram removidos para quantificação da mieloperoxidase tecidual. Resultados: Não houve diferenças estatísticas entre grupos em todos os parâmetros analisados. Conclusão: Nesse modelo, a dieta enriquecida com rosiglitazona não protegeu contra a lesão de isquemia e reperfusão hepática.

Descritores: Isquemia. Reperfusão. Fígado. Ratos.

${ }^{1}$ Research performed of Transplantation Division, Laboratory of Medical Investigation \#LIM37, Department of Gastroenterology, School of Medicine, University of São Paulo (USP), Brazil. 


\section{Introduction}

Liver ischemia-reperfusion injury (LIRI) is a phenomenon inevitable after hepatic surgery, liver transplantation, shock and trauma ${ }^{1}$. Hepatic ischemia-reperfusion leads to an acute inflammatory response, causing significant hepatocellular damage and organ dysfunction. Mechanisms of LIRI involve complex and multiple pathways, including the direct ischemic cellular damage as well as the cell injury due to the activation of inflammatory response after reperfusion ${ }^{2}$. The accumulation of inflammatory cells contributes to the progression of parenchymal injury. Despite the recent improvements in liver preservation and surgical techniques, LIRI remains an important clinical complication.

An important pathway involved in inflamation and regeneration is the peroxisome proliferator-activated receptors (PPARs) family. PPARs are members of the nuclear hormone receptor superfamily of ligand-dependent transcription factors ${ }^{3}$. The PPAR subfamily comprises three members, PPAR- $\alpha$, PPAR- $\beta$, and PPAR- $\gamma^{4}$. Thiazolidinediones (pioglitazone, troglitazone, and rosiglitazone) are synthetic PPAR- $\gamma$ agonists and they act to enhance insulin sensitivity and reduce serum glucose in diabetic patients ${ }^{5}$. Therefore, they are now widely used as antidiabetic agents. Besides the antidiabetic activity, it has been recently recognized to have other various physiological roles including inflammation. In particular, PPAR- $\gamma$ may be a protective regulator against ischemic damage. In the liver, it has been suggested that PPAR $-\gamma$ agonists are protective against liver injury in chronic disease conditions such as cirrhosis and fibrosis ${ }^{6}$. A recent study showed that PPAR $-\gamma$ plays an inhibitory role in LIRI and the stimulation by selective agonist has a significant beneficial effect in mice. This protective effect of pioglitazone was associated with downregulation of the local expression of several potent proinflammatory cytokines, chemokines and adhesion molecules after reperfusion ${ }^{7}$. One speculate if PPAR- $\gamma$ agonists may have a therapeutic role in liver ischemia-reperfusion injury.

Our aim was to determine whether rosiglitazone-enriched diet could offer protection in a classical model of liver ischemia-reperfusion injury in rats.

\section{Methods}

The study was designed in accordance with the Guide for the Care and Use of Laboratory Animals published by the US National Institutes of Health and the Guidelines of Animal Experimentation of the University of São Paulo School of Medicine, São Paulo, SP, Brazil, for the care and use of laboratory animals. Male Wistar rats weighing $250 \pm 5 \mathrm{~g}$ were housed in a room with a temperature of $23 \pm 1{ }^{\circ} \mathrm{C}$ and a controlled $12-\mathrm{h}$ light/dark cycle. Animals were anestethized with ketamin 5\% (30 mg/kg) and xylazine $2 \%(30 \mathrm{mg} / \mathrm{kg}$ ) intraperitonially. During the experiment, animals were warmed by a halogen light $(45 \mathrm{~W}, 127 \mathrm{~V})$ and corporeal temperature was monitorized by a rectal digital thermometer (YSI Precision 4000A thermometer, USA) and kept around $37^{\circ} \mathrm{C}$. Animals were allowed to spontaneous ventilation with an oxygen-enriched mixture (40\%) dur- ing all the procedure.

The experimental protocol was pre-approved by Ethics Commission of the Hospital das Clínicas , University of São Paulo, Brazil.

Twenty six male Wistar rats, provided by the Medical Investigation Laboratory \#37 (LIM-37) were used. Two days before the experiment, rats were divided into 2 groups: Control Group ( $n=13)$ : rats fed with standard diet; Rosi Group $(n=13)$ : rats fed with a powdered standard diet supplemented with rosiglitazone to produce mixture with $92 \mathrm{mg} / \mathrm{kg}$. All animals were allowed to have free access to diet and water. The food intake in milligrams was monitored daily $(2.8 \mathrm{mg} / \mathrm{rat} /$ day $)$.

Animals were than submitted to liver ischemiareperfusion procedure. Briefly, a median laparotomy was performed and the pedicle of median and left anterolateral segments was dissected, exposed and clamped with an atraumatic microvascular bulldog clamp. In this technique, pedicle clamping is completely reversible, avoiding intestinal and caval stasis. After clamping, the abdominal wall was closed with ininterrupted 4-0 nylon suture in order to avoid dehydration. After 1 hour of partial hepatic ischemia, the clamp was removed to initiate hepatic reperfusion.

After 2 or 24 hours (Control and Rosi Groups), the animals were anestethized again and $5 \mathrm{ml}$ of blood was collected by cardiac punction for biochemical analysis. Rats were than killed by aorta section. The liver was collected and identified as "ischemic liver" and "non-ischemic liver" for malondialdehyde analysis. For histological assessment liver was collected 24 hours after reperfusion.

Pulmonary artery was catheterized via right ventriculum with a plastic 2,0 mm diameter tube (Silastic, Dow Corning, no. 602.175 ) and $40 \mathrm{ml}$ of saline $0.9 \%$ was infused, at a rate of $10 \mathrm{ml} / \mathrm{min}$. Lungs were removed for tissue myeloperoxidase quantification.

\section{Liver enzymes}

Hepatic enzymes [alanine aminotransferase (ALAT), aspartate aminotransferase (ASAT), alkaline phosphatasis (AP) and gamma-glutamyltransferase (GGT)] levels were quantified using a clinical chemistry kit (Testline - SG Tecnologia Clínica, São Paulo, Brazil) on Cobas Mira analyzer, according to the manufacturer's instructions.

\section{TNF- $\alpha$ and interleukines}

Serum TNF- $\alpha$, IL-6 and IL-10 concentrations were measured in duplicate using a commercially available enzymelinked immunosorbent assay kit (Biosource International Cytoscreen, Camarillo, CA) according to the manufacturer's instructions. The concentrations were expressed in $\mathrm{pg} / \mathrm{ml}$.

\section{Pulmonary myeloperoxidase}

Pulmonary myeloperoxidase (MPO) activity was used as an indicator of neutrophil accumulation. Samples of lung tissue homogenized with a Polytron ${ }^{\circledR}$ homogenizer using a buffer 
that contains $0.5 \%$ hexadecyltrimethyl ammonium bromide, $5 \mathrm{mmol} / \mathrm{L}$ EDTA, and $50 \mathrm{mmol} / \mathrm{L}$ phosphate at $\mathrm{pH}$ 6.0. Homogenized samples were sonicated and centrifugated (3000g, 30 minutes) at $4^{\circ} \mathrm{C}$. MPO activity in the supernatant was assayed by measuring the change in $\mathrm{A}_{460}$ resulting from the decomposition of $\mathrm{H}_{2} \mathrm{O}_{2}$ in the presence $\mathrm{O}$-dianiside. Results are expressed as optimal density (OD) at $490 \mathrm{~nm}$.

\section{Malondialdehyde measurement}

Malondialdehyde (MDA) levels in the samples were determined to obtain quantitative estimation of the membrane lipid oxidative damage. MDA was assayed in terms of thiobarbituric acid reactive substrats. The thiobarbituric acid method was used to quantify lipid peroxidation in liver, measured as thiobarbituric acid-reactive substances (TBARS). Liver tissues $(100 \mathrm{mg} / \mathrm{mL})$ were homogeneized in $1.15 \% \mathrm{KCl}$ buffer, and centrifuged at $14,000 \mathrm{~g}$ for $20 \mathrm{~min}$. The supernatant was then stores at $-70^{\circ} \mathrm{C}$. an aliquot of the supernatant was added to a reaction mixture of $1.5 \mathrm{~mL} 0.8 \%$ thiobarbituric acid, $200 \mu \mathrm{L}$ $8.1 \%(\mathrm{v} / \mathrm{v}) \mathrm{SDS}, 1.5 \mathrm{~mL} 20 \%$ (v/v) acetic acid, $\mathrm{pH} 3.5$, and $300 \mu \mathrm{L}$ distilled $\mathrm{H}_{2} \mathrm{O}$, and heated to $90^{\circ} \mathrm{C}$ for $45 \mathrm{~min}$. After cooling to room temperature, the samples were cleared by centrifugation at $10,000 \mathrm{~g}$ for $10 \mathrm{~min}$, and their absorbance was measured at $532 \mathrm{~nm}$ using malondialdehyde bis (dimethyl acetal) as an external standard. The quantity of lipid peroxides is reported in nmol malondialdehyde (MDA) equivalents/mg protein.

\section{Histological analysis}

Fragments of liver tissue previously fixed in $10 \%$ formalin solution were processed and stained with hematoxylineosin. The following histological variables were assessed: parenchymal detrabeculation, presence of apoptosis, cellular edema and congestion.

\section{Statistical analysis}

Comparisons between groups were statistically analyzed using a GraphPad Prism 2.01 software (San Diego, CA, USA). A nonparametric test (Mann-Whitney) was performed since the data distribution was considered as non-Gaussian. Mean values and SEM were displayed in graphics only as additional information. Differences were considered statistically significant when $p<0.05$

\section{Results}

There were no statistical differences between Control Group and Rosi Group concerning liver enzymes after two and twenty-four hours of reperfusion (Figures 1-4).
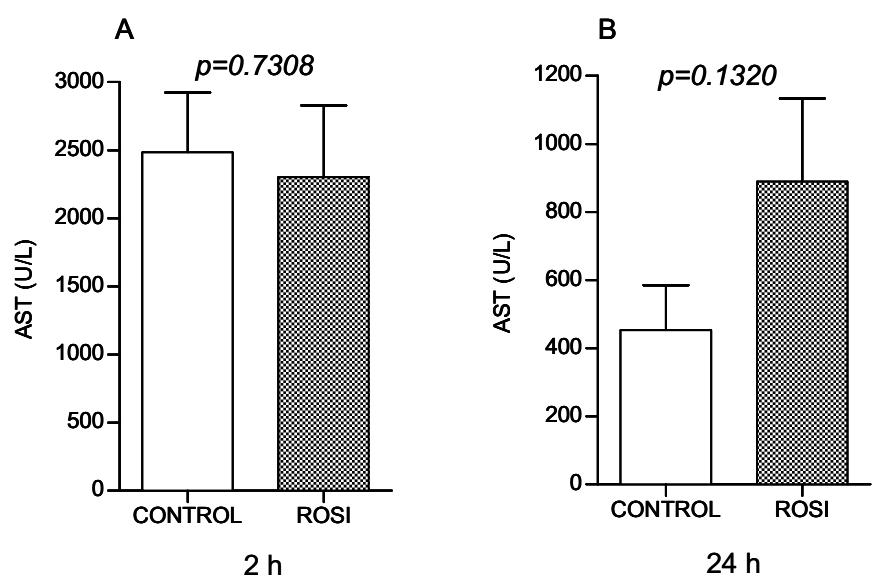

FIGURE 1 - Serum levels of aspartate aminotransferase (ALT) after two hours (A: Control Group: 2484 \pm 438.4 , Rosi Group: 2301 \pm 527.5 ) and twenty-four hours (B: Control Group: 453.3 \pm 131.3 , Rosi Group: $888.3 \pm 245.1)$ of reperfusion

\section{$A L T$}
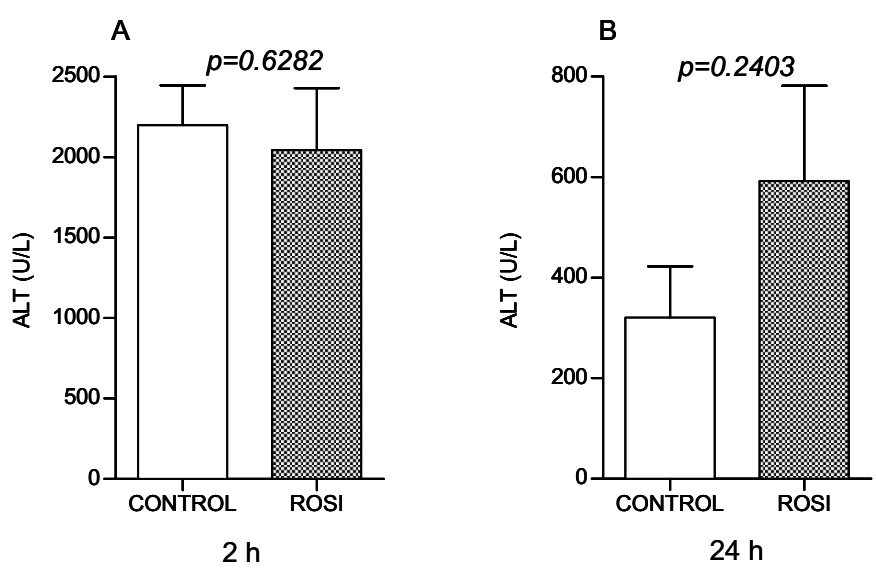

FIGURE 2 - Serum levels of alanine aminotransferase after two hours (A: Control Group: $2197 \pm 247.4$, Rosi Group: $2044 \pm 384.7$ ) and twenty-

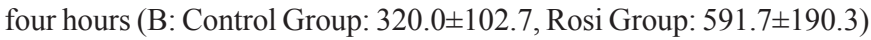
of reperfusion 

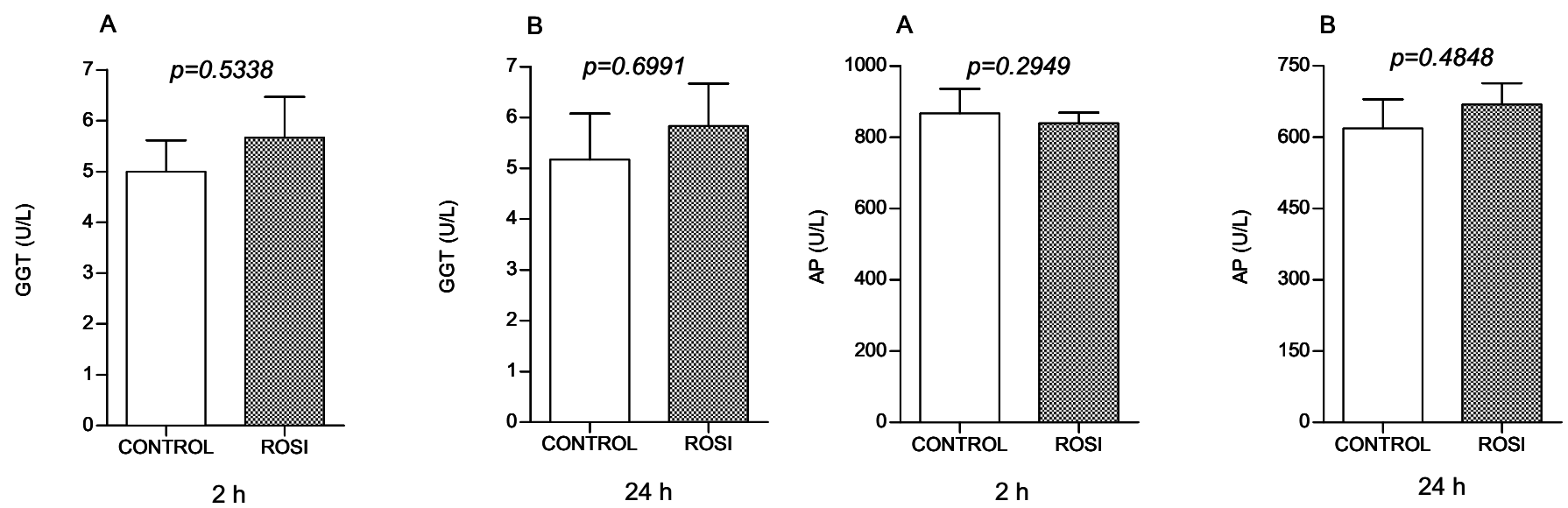

FIGURE 3 - Serum levels of gamma-glutamyltransferase. (GGT) af-

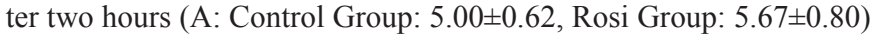
and twenty-four hours (B: Control Group: 5.16 \pm 0.91 , Rosi Group: $5.83 \pm 0.83$ ) of reperfusion

FIGURE 4 - Serum levels of alkaline phosphatasis (AP) after two

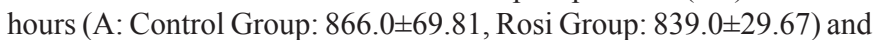
twenty-four hours (B: Control Group: 617.8 \pm 61.6 , Rosi Group: $668.5 \pm 45.1)$ of reperfusion

The cytokines TNF- $\alpha$, IL-6, IL-10 were assessed only after two hours of reperfusion and differences between Control and Rosi Groups were not significant as well (Figure 5).
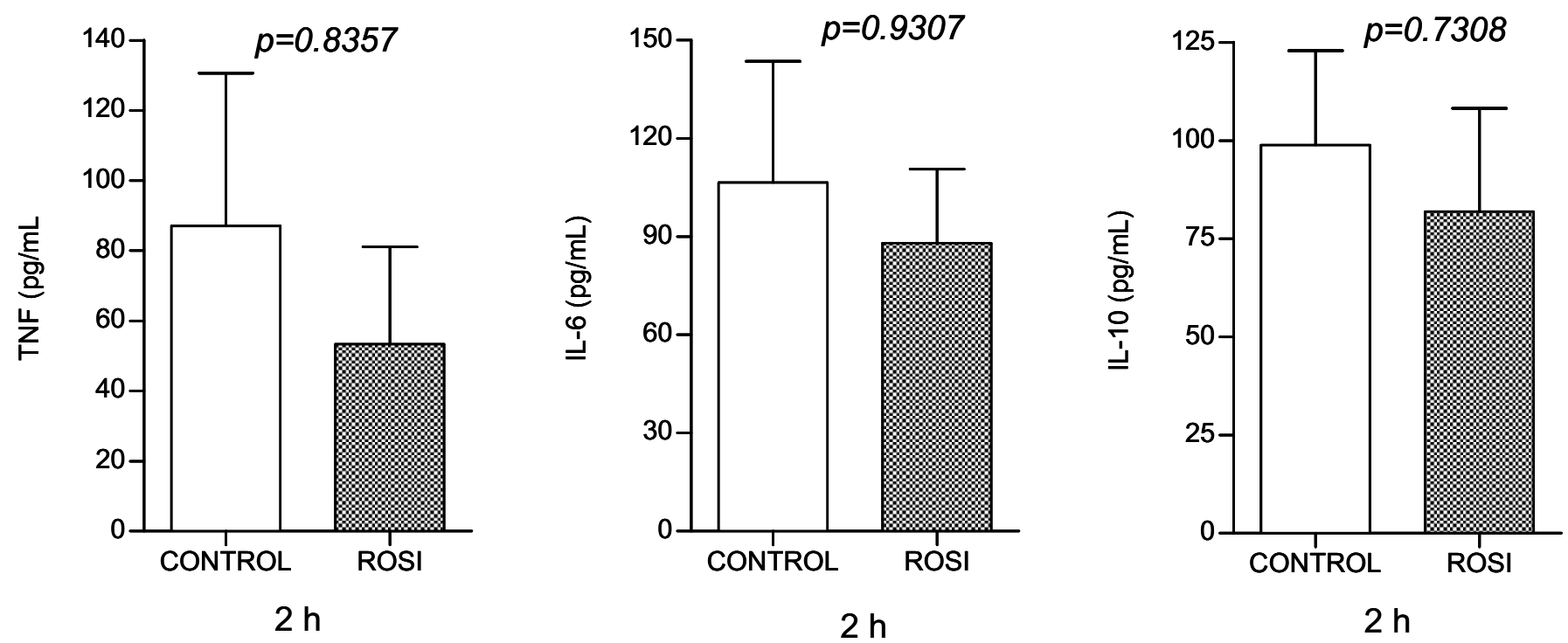

FIGURE 5 - Serum levels of tumor necrosis alpha (TNF- $\alpha$ ) (Control Group: 87.0 \pm 43.64 , Rosi Group: 53.33 \pm 27.75$)$, interleukin-6 (IL-6) (Control Group: 106.5 \pm 37.11 , Rosi Group: 88.0 \pm 22.55 ), interleukin-10 (IL-10) (Control Group: 98.86 \pm 24.05 , Rosi Group: 81.83 \pm 26.33 ) two hours of reperfusion 
Pulmonary MPO (Figure 6) and hepatic MDA - in the ischemic (Figure 7) and non-ischemic liver (Figure 8) - were also analyzed after two and twenty-four hours of reperfusion in Control and Rosi Groups. Differences between the groups were not observed.
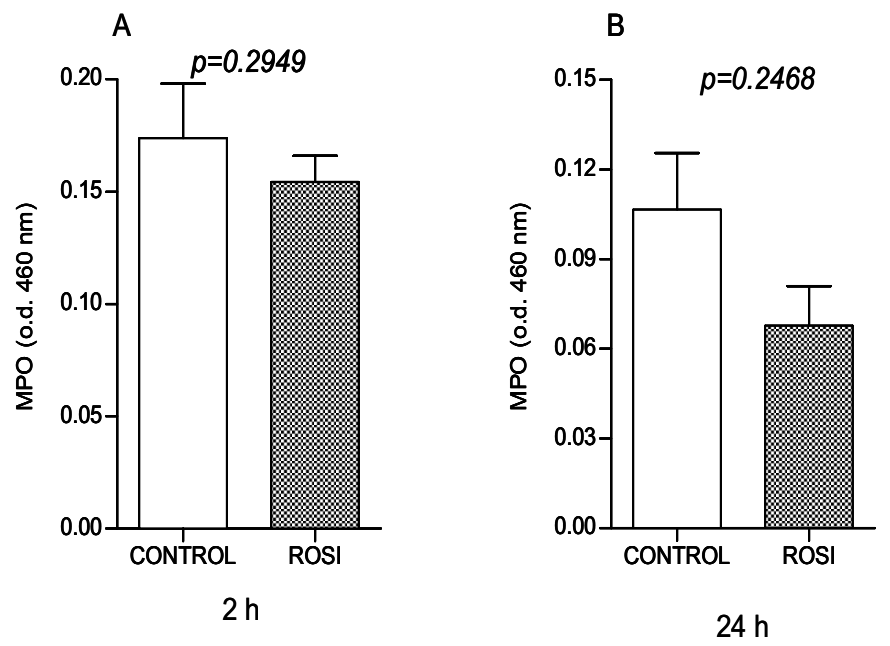

FIGURE 6 - Pulmonary myeloperoxidase (MPO) activity after two hours (A: Control Group: $0.173 \pm 0.02$, Rosi Group: $0.154 \pm 0.011$ ) and twenty-four hours (B: Control Group: 0.1065 \pm 0.019 , Rosi Group: $0.0676 \pm 0.013)$ of reperfusion

\section{Ischemic Liver}

A

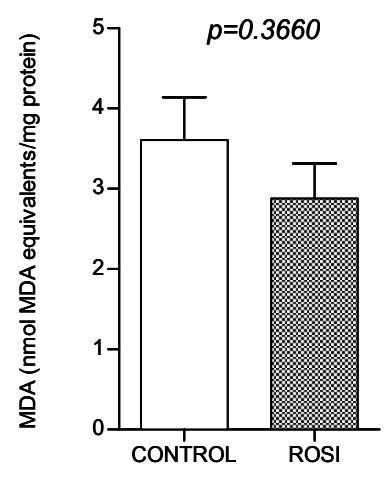

$2 \mathrm{~h}$
B

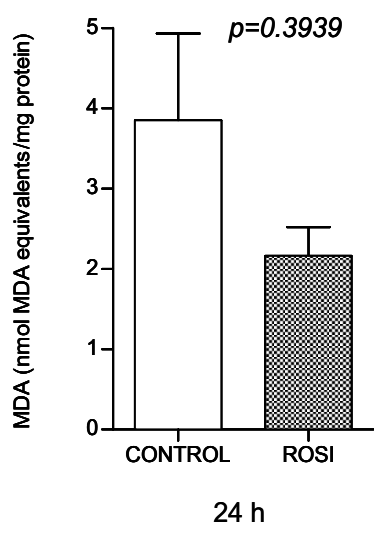

FIGURE 7 - Thiobarbituric acid-reactive substances-malondialdehyde (MDA) equivalents in ischemic liver samples after two hours (A: Control Group: $3.6 \pm 0.53$, Rosi Group: $2.87 \pm 0.43$ ) and twenty-four hours (B: Control Group: $3.84 \pm 1.08$, Rosi Group: $2.16 \pm 0.36$ ) of reperfusion
Non Ischemic Liver

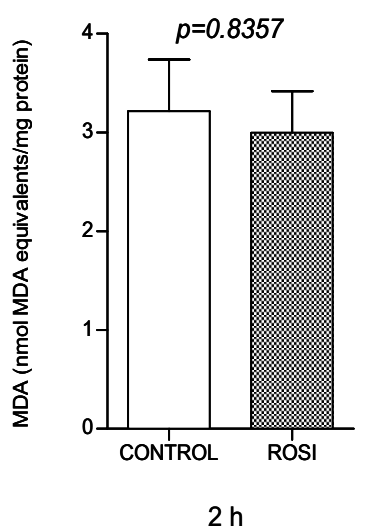

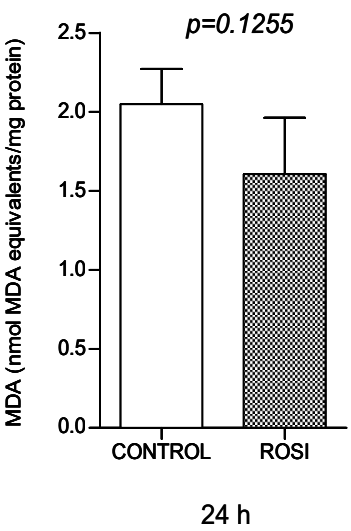

FIGURE 8 - Thiobarbituric acid-reactive substances-malondialdehyde (MDA) equivalents in non ischemic liver samples after two hours (A: Control Group: $3.21 \pm 0.52$, Rosi Group: $2.99 \pm 0.42$ ) and twenty-four hours (B: Control Group: 2.05 \pm 0.22 , Rosi Group: 1.60 \pm 0.36 ) of reperfusion. C: Comparison between A and B only for Rosi Group (2 hours: $2.99 \pm 0.42,24$ hours: $1.60 \pm 0.36$ )

Histological assessment of ischemic and non-ischemic lobes (only after 24 hours of reperfusion) was performed by an experienced pathologist and showed a menagerie of mild alterations (detrabeculation, apoptotic bodies, congestion) not different between the groups (photographies not shown).

\section{Discussion}

Pro-inflammatory cytokines are up-regulated during acute liver injury. The increment of TNF- $\alpha$ and IL- 6 has been associated with ischemic damage and lack of tissue protection ${ }^{8}$. They are responsible for the induction of neutrophil sequestration in the lungs 9 , analyzed by lung leukocyte recruitment (MPO). On the other hand, IL-10 appears to have an attenuating effect on organ damage, due to its anti-inflammatory properties $^{10}$.

There are some evidences that PPAR- $\gamma$ agonists may suppress the production of IL-1, IL- 6 and TNF- $\alpha$ in stimulated human peripheral blood monocytes ${ }^{11}$.

The potential protective effect of thiazolidinediones in LIRI are under investigation. These drugs might have a role in clinical situations such as hepatectomies and liver transplantation. Theoretically, a patient could receive rosi or pioglitazone prior to a liver resection when ischemia is planned. Similarly, a liver donor could receive these drugs in intensive care unit before multiorgan retrieval, in order to protect tissues from ischemia reperfusion injury.

In this study, we tested the effects of a rosiglitazoneenriched diet in a classical model of LIRI in rats, focusing in the early (2hs) and delayed (24hs) effects of the drug. 
We assessed classical markers of liver injury (AST, ALT, AP, GGT), pro- and anti-inflammatory cytokines (IL-6, TNF- $\alpha$ and IL-10) and lung leukocyte recruitment (MPO). We also evaluated lipid peroxidation (MDA) and liver histology in ischemic and non-ischemic liver in both groups.

Analyzing our results, we found that liver enzymes peaks (ALT, AST, AP and GGT) reached values that confirm clamping promoted effective hepatocyte injury. Statistical differences between Control and Rosi groups were not significant. It means that rosiglitazone did not modify the degree of injury inflicted to the hepatocytes.

Similarly, TNF- $\alpha$, IL-6, IL-10 and lung myeloperoxidase (MPO) was not modulated by rosiglitazone administration.

Nevertheless, others researchers found beneficial effects of thiazolidinediones administration in a different model of LIRI in mice. Kuboki et al. demonstrated that PPAR- $\gamma$ activation by rosiglitazone offers protection against hepatic ischemia (90 minutes) followed by eight hours of reperfusion. They showed that PPAR- $\gamma$ is constitutively activated in normal liver and that hepatic ischemia causes a rapid decrease in PPAR- $\gamma$ DNA binding. They suggest that PPAR $-\gamma$ is an important endogenous regulator of, and potential therapeutic target for, ischemic liver injury ${ }^{12}$. The differences between our and Kuboki's results may relay on the fact they applied a longer period of ischemia.

Lipid peroxidation refers to the oxidative degradation of lipids. It is the process where free radicals transfer electrons from the lipids to cell membranes, resulting in cell damage. The main final product of this reaction is malondialdehyde (MDA) and it is reactive with thiobarbituric acid (TBARS) ${ }^{13}$. To our knowledge, this is the first time that the potential capacity of rosiglitazone to ameliorate lipid peroxidation induced by LIRI was tested in an animal model. Our results did not show a significant difference between Rosi and Control groups concerning MDA analysis.

Despite these preliminary negative results, there are evidences that thiazolidinediones may have an important role in LIRI and further studies will be addressed in this direction.

\section{References}

1. Lemasters JJ, Thurman RG. Reperfusion injury after liver preservation for transplantation. Ann Rev Pharmacol Toxicol. 1997;37:327-38. 2. Jaeschke H. Mechanisms of Liver Injury. II. Mechanisms of neutrophil-induced liver cell injury during hepatic ischemia-reperfusion and other acute in.ammatory conditions. Am J Physiol Gastrointest Liver Physiol. 2006;290(6):G1083-G88.

3. Kersten S, Desvergne B, Wahli W. Roles of PPARs in health and disease. Nature. 2000;405(6785):421-4.

4. Michalik L, Wahli W. Peroxisome proliferator-activated receptors: three isotypes for a multitude of functions. Curr Opin Biotechnol. 1999;10(6):564-70.

5. Plutzky J. The potential role of peroxisome proliferator-activated receptors on in.ammation in type 2 diabetes mellitus and atherosclerosis. Am J Cardiol. 2003;92(4A):34J-41J.

6. Galli A, Crabb DW, Ceni E, Salzano R, Mello T, Svegliati-Baroni G, Ridolfi F, Trozzi L, Surrenti C, Casini A. Antidiabetic thiazolidinediones inhibit collagen synthesis and hepatic stellate cell activation in vivo and in vitro.Gastroenterology. 2002;122(7):1924-40. 7. Akahori T, Sho M, Hamada K, Suzaki Y, Kuzumoto Y, Nomi T, Nakamura S, Enomoto K, Kanehiro H, Nakajima Y. Importance of peroxisome proliferator-activated receptor-gamma in hepatic ischemia/ reperfusion injury in mice. J Hepatol. 2007;47(6):784-92.

8. Teoh N, Leclercq I, Pena AD, Farrell G. Low-dose TNF-alpha protects against hepatic ischemia-reperfusion injury in mice: implications for preconditioning. Hepatology. 2003;37(1):118-28.

9. Colletti LM, Remick DG, Burtch GD, Kunkel SL, Strieter RM, Campbell DA Jr. Role of tumor necrosis factor-alpha in the pathophysiologic alterations after hepatic ischemia/reperfusion injury in the rat. J Clin Invest. 1990;85(6):1936-43.

10. Le Moine O, Louis H, Demols A, Desalle F, Demoor F, Quertinmont $\mathrm{E}$, Goldman M, Devière J. Cold liver ischemia-reperfusion injury critically depends on liver T cells and is improved by donor pretreatment with interleukin 10 in mice. Hepatology. 2000 ;31(6):1266-74.

11. Jiang C, Ting AT, Seed B. PPAR-gamma agonists inhibit production of monocyte inflammatory cytokines. Nature. 1998;391(6662):82-6. 12. Kuboki S, Shin T, Huber N, Eismann T, Galloway E, Schuster R, Blanchard J, Zingarelli B, Lentsch AB. Peroxisome proliferator-activated receptor-gamma protects against hepatic ischemia/reperfusion injury in mice. Hepatology. 2008;47(1):215-24.

13. Marnett LJ. Lipid peroxidation-DNA damage by malondialdehyde. Mutat Res. 1999;424(1-2):83-95.

\section{Correspondence:}

Dr. Antônio Roberto Franchi-Teixeira

Laboratório de Investigação Médica - LIM 37

Faculdade de Medicina - FMUSP

Av. Dr. Arnaldo, 455/sala 3206

01246-903 São Paulo - SP Brazil

Phone: (55 11)3061-8319 / 8558-8426

drrteixeira@uol.com.br
Conflict of interest: none Financial source: none

\section{How to cite this article}

Teixeira ARF, Molan NT, Bellodi-Privato M, Coelho AM, Leite KR, Seguro AC, Bacchella T, Machado MCC. Rosiglitazoneenriched diet did not protect liver ischemia-reperfusion injury in a rat model. Acta Cir Bras. [serial on the Internet] 2008 JulyAug;23(4). Available from URL: http://www.scielo.br/acb 